\title{
CAMA
}

Centre for Applied Macroeconomic Analysis

\section{Electricity Market Integration, Decarbonisation and Security of Supply: Dynamic Volatility Connectedness in the Irish and Great Britain Markets}

\section{CAMA Working Paper 42/2020 Aprill 2020}

\section{Hung Do}

School of Economics and Finance, Massey University

\section{Rabindra Nepal}

School of Accounting, Economics and Finance, University of Wollongong

Centre for Contemporary Australasian Business and Economics Studies (CCABES),

University of Wollongong

Centre for Applied Macroeconomic Analysis, ANU

\section{Tooraj Jamasb}

Copenhagen School of Energy Infrastructure, Copenhagen Business School

\section{Abstract}

This study investigates the volatility connectedness between the Irish and Great Britain electricity markets and how it is driven by changes in energy policy, institutional structures and political ideologies. We assess various aspects of this volatility connectedness including static (unconditional) vs dynamic (conditional), symmetric vs asymmetric characteristics between 2009 and 2018. We find that volatility connectedness is time varying and is significantly affected by important events, policy reforms or market re-designs such as Brexit, oil price slump, increasing share of renewables, and fluctuations in the exchange rates. Our asymmetric analysis shows that the magnitude of the good volatility connectedness is marginally larger than that of the bad volatility connectedness. Our result suggests that good volatility levels would be even higher once the Irish market adopts the carbon price floor. Therefore, supporting renewable generation by setting an appropriate carbon price in interconnected wholesale electricity markets will improve market integration. 


\section{Keywords}

Market integration, electricity, renewable, energy policy, volatility

\section{JEL Classification}

D4, L94, Q2, Q4

\section{Address for correspondence:}

(E) cama.admin@anu.edu.au

ISSN 2206-0332

The Centre for Applied Macroeconomic Analysis in the Crawford School of Public Policy has been established to build strong links between professional macroeconomists. It provides a forum for quality macroeconomic research and discussion of policy issues between academia, government and the private sector.

The Crawford School of Public Policy is the Australian National University's public policy school, serving and influencing Australia, Asia and the Pacific through advanced policy research, graduate and executive education, and policy impact. 


\title{
Electricity Market Integration, Decarbonisation and Security of Supply: Dynamic Volatility Connectedness in the Irish and Great Britain Markets
}

\author{
Hung Do ${ }^{a}$, Rabindra Nepal ${ }^{b}$ and Tooraj Jamasb ${ }^{c}$ \\ ${ }^{\mathrm{a}}$ School of Economics and Finance, Massey University, New Zealand \\ ${ }^{\mathrm{b}}$ School of Accounting, Economics and Finance \& Centre for Contemporary Australasian Business \\ and Economics Studies (CCABES), University of Wollongong \\ Centre for Applied Macroeconomic Analysis, CAMA \\ ${ }^{\mathrm{c}}$ Copenhagen School of Energy Infrastructure, Copenhagen Business School
}

\begin{abstract}
This study investigates the volatility connectedness between the Irish and Great Britain electricity markets and how it is driven by changes in energy policy, institutional structures and political ideologies. We assess various aspects of this volatility connectedness including static (unconditional) vs dynamic (conditional), symmetric vs asymmetric characteristics between 2009 and 2018. We find that volatility connectedness is time varying and is significantly affected by important events, policy reforms or market redesigns such as Brexit, oil price slump, increasing share of renewables, and fluctuations in the exchange rates. Our asymmetric analysis shows that the magnitude of the good volatility connectedness is marginally larger than that of the bad volatility connectedness. Our result suggests that good volatility levels would be even higher once the Irish market adopts the carbon price floor. Therefore, supporting renewable generation by setting an appropriate carbon price in interconnected wholesale electricity markets will improve market integration.
\end{abstract}

Key words: Market integration, electricity, renewable, energy policy, volatility.

JEL classifications: D4, L94, Q2, Q4.

${ }^{a}$ Corresponding author.

Email: h.do@massey.ac.nz (Hung Do),rnepal@@uow.edu.au (Rabindra Nepal), and tj.eco@cbs.dk (Tooraj Jamasb).

Acknowledgements: We are thankful to Dr. Laura Malaguzzi Valeri from the World Resources Institute and Emma Tribe from ELEXON for providing us the data. 


\section{Introduction}

"The completion of a fully functioning, interconnected and integrated internal energy market......is central to Europe's competitiveness and must not be fragmented." (President Barroso, European Commission, 2013).

The integration of wholesale energy markets remains a prioritised policy instrument in delivering the three distinct but interrelated energy policy goals of affordability, security of supply and environmental sustainability. The theoretical appeal of an integrated energy market is in terms of improving security of supply, enhancing competition and inducing greater economic efficiency, as well as rendering environmental benefits by optimising variations in resource mix and demand patterns (Newbery et al., 2016). Hence, advanced economies such as the European Union (EU) began to consider a European Single Market for Electricity as early as 1986 (Pollitt, 2019) while OECD economies like Australia established the National Electricity Market in 1998 (Nepal and Foster, 2016). As a result, a few studies have attempted to measure the progress towards energy markets integration in the aftermath of energy markets liberalisation and gauge its effectiveness (Joskow. 2019).

At the same time, volatility across wholesale electricity markets is expected to rise with growing shares of renewables with intermittent supply characteristics. ${ }^{1}$ Renewable energy is viewed a viable alternative energy in response to the growing concern about climate change, fossil fuel depletion, energy security issues, technology innovation, and high and volatile prices of petroleum-based fuels (Ferrer et al., 2018). In interconnected electricity markets, examination of volatility connectedness or spillovers and its dynamics facilitate the study of information efficiency by unravelling the different information transmission channels.

\footnotetext{
${ }^{1}$ Following the volatility literature, we define volatility as the standard deviation of asset prices (e.g., Engle, 1982; Bollerslev, 1986; Andersen et al., 2001, 2003; Barndorff-Nielsen, 2002; Barndorff-Nielsen et al., 2010).
} 
Studying volatility connectedness or spillovers in interconnected electricity markets contributes to understanding of the volatility transmission mechanism and provides useful information for demand and supply-side market participants. ${ }^{2}$ Our study contributes to the scare literature by examining volatility connectedness from different angles, including static (unconditional) vs dynamic (conditional) and symmetric vs asymmetric, in the interconnected wholesale electricity markets between Ireland and Great Britain.

We analyse the static and dynamic aspects of the volatility connectedness using the Diebold and Yilmaz (2012) approach. While the static analysis shows how the volatilities are connected over the sample period on average, the dynamic analysis measures volatility connectedness at a given day. That is, the dynamic analysis shows how volatility connectedness behaves conditional on changes absorbed by the market in a given day, such as events, policy reforms, and market re-designs. To analyse the asymmetry of volatility connectedness, we decompose the volatilities into "good" and "bad" volatilities. "Good" volatility is defined as variation caused by the positive changes in electricity prices, while "bad" volatility is associated with uncertainty due to the negative movements in prices. This approach is consistent with the empirical set-up in Barunik et al. (2015) and Apergis et al. (2017b). ${ }^{3}$

Studies confined to symmetric volatility connectedness analysis cannot capture how physically interconnected markets are linked through the level of asymmetry of returns distribution. In other words, this linkage can result from the connectedness of upside (downside) risks between interconnected regional markets which requires an analysis of the asymmetric

\footnotetext{
${ }^{2}$ In this study, we use the term "volatility connectedness" and "volatility spillovers" interchangeably following a number of recent studies such as Diebold and Yilmaz $(2014,2016)$ and Demirer et al. (2018). For empirical analyses of volatility connectedness, we employ the Diebold and Yilmaz $(2012,2014)$ method, which is outlined in the Appendix. The idea of the connectedness index is intuitive yet rigorous and replicable that it illustrates the proportion of forecast error variance of one variable caused by shocks to another variable.

${ }^{3}$ Barunik et al. (2015) separate volatilities into good and bad volatilities to quantify the asymmetries in the volatility spillovers among petroleum commodities (crude oil, gasoline and heating oil. Meanwhile, Apergis et al. (2017b) employ the good and bad volatility approach to uncover the asymmetric volatility spillovers in the Australian National Electricity markets.
} 
volatility in interconnected electricity markets. Asymmetric connectedness also tends to be a source of contagion, which could have important implications for the implementation of energy and electricity policies in a transforming energy sector (Apergis et al,. 2017b).

Therefore, investigation into the presence of asymmetric volatility connectedness in electricity markets is important for tracing the source of connectedness which could be institutional, policy-oriented and events driven. Despite such importance, only one notable study by Apergis et al. (2017b) has examined the presence of asymmetric volatility in electricity markets even though the presence of asymmetric connectedness effects across and within energy such as oil and natural gas markets has been previously studied (Chang et al., 2010; Sadorsky, 2012; Ewing and Malik, 2013).

This study also extends the literature on the presence of asymmetric volatility connectedness in electricity markets by focusing on Ireland and Great Britain. These provide a strong case for studying the presence, effects and source of dynamic and asymmetric volatility connectedness. This is because these two markets need to accommodate the energy and environmental policy changes stemming from addressing affordability, decarbonisation and security of supply objectives in line with the three European Commission (EC) Directives (energy packages) (see 96/92/EC (1996); 03/54/EC (2003) and 09/72/EC (2009)) $)^{4}$ as well as broader institutional and political changes such as Brexit.

The Irish market is unique in terms of operation and establishment because the Northern Ireland Authority for Utility Regulation (NAIRU) and Ireland's Commissions for Energy Regulation (CER) began jointly regulating the all-island Single Electricity Market (SEM) since

\footnotetext{
${ }^{4}$ Pollitt (2019) describes in depth the details envisaged by these three different directives.
} 
November $1,2007^{5}$. The SEM is the market of the island of Ireland and was not created by the EU per se but rather is an indigenous development set up bilaterally by the British and Irish Governments and subsequently signed into law in both jurisdictions (Wallace, 2019). On 1 October 2018, the new wholesale electricity market arrangement for Ireland and Northern Ireland (the Integrated Single Electricity Market or I-SEM) was introduced in line with the EU's “Target Electricity Model” (EC, 2014). The model seeks to realize a more integrated, open and efficient pan-European electricity market. Paradoxically, the movement towards the withdrawal of the United Kingdom (UK) from the EU (known as Brexit) has simultaneously threatened the role of the UK electricity market in fostering an integrated EU electricity market in a opposite direction, at least theoretically (Pollitt, 2017). Likewise, the isolation of the ISEM from continental Europe has resulted in just two high voltage direct current (HDVC) interconnectors link: the Moyle interconnector and the East-West Interconnector (EWIC). The Moyle interconnector is in operation since 2001 connecting SEM with Great Britain (GB) amounting to almost $4.7 \%$ (about $500 \mathrm{MW}$ ) of total SEM generation capacity (Nepal and Jamasb, 2012). The EWIC is also a 500 MW high-voltage direct current power cable and in operation since 2012 connecting the Irish and British electricity markets. How has the market integration effects evolved over time between the two markets in light of ongoing regulatory, institutional and political changes? Did certain policy and institutional events induce greater effects on market integration than others? What issues must these two markets consider in the context of EU electricity market integration because of the uncertainty around Brexit?

Past studies of market integration between these two island markets suggested the possibility of improving market integration via investments in transmission infrastructures such as interconnectors. Nepal and Jamasb (2012) using cointegration and Kalman filter analysis

\footnotetext{
${ }^{5}$ The CER changed its name to the CRU in 2017 to better reflect the expanded powers and functions of the organisation as Ireland's independent energy and water regulator where CRU now stands for the Commission for Regulation of Utilities.
} 
concluded that improving liquidity of wholesale markets might be a crucial factor in the market integration process. The state of market integration between SEM and GB was shown to be low but improving. An earlier study by Malaguzzi Valeri (2009) echoed that social welfare increases with interconnection, although at a decreasing rate. Based on a simulation results, the study documented positive effects on competition in the SEM as the amount of interconnection increases between these two markets. Dean et al. (2015) compared the wholesale electricity prices between SEM, and BETTA (British Electricity Trading and Transmission Arrangements) in Great Britain to conclude that wholesale price in BETTA is set too low to cover generation costs but is compensated by large retail margins than the SEM.

These two markets provide useful lessons for integrating the EU electricity market with growing intermittent renewables (Newbery, 2017). No previous studies have undertaken a volatility connectedness analysis including examination of the asymmetry of volatility connectedness between these two markets. The present study reduces this gap as the first study to undertake an examination of volatility connectedness between the all-island Single Electricity Market and the Great Britain wholesale electricity market. By doing so, we also extend the scare literature of empirical findings based on asymmetric volatility connectedness. The findings are relevant not only to the EU but also globally as the establishment of wholesale electricity markets and improving market integration among regional markets through direct physical interconnections is ongoing in different regions of the world ${ }^{6}$.

The remainder of the paper is structured as follows. Section 2 provides a brief literature review on electricity market integration. Section 3 describes the methodologies used. Section 4 describes the data used in the empirical analysis. Section 5 discusses the empirical results, and finally, Section 6 concludes the paper.

\footnotetext{
${ }^{6}$ See e.g., Pollitt (2019); Singh et al. (2018) and Oseni and Pollitt (2016) on the development of regional electricity markets around the world.
} 


\section{Literature Review}

Most studies on electricity markets integration have involved studying the long-run spot price trends relationships between separate but physically interconnected liberalised markets such as in the US (e.g., Woo, Lloyd- Zanetti and Horowitz, 1997; De Vany and Walls, 1999 and Dempster, Issacs and Smith, 2008); in Europe (see e.g., Zachmann, 2008; CastagnetoGissey; Chaves and Fellani, 2014; Menezes and Houllier, 2014; Gugler et al. 2018) and in Australia (Nepal and Foster, 2016; Apergis et al. 2017a). Majority of these studies have used the bivariate and systems-based cointegration tests and Granger causality tests to test for long run price relationships (Woo, Lloyd- Zanetti and Horowitz, 1997; De Vany and Walls, 1999 and Dempster, Issacs and Smith, 2008; Gugler et al. 2018; Nepal and Foster, 2016).

However, cointegration analysis assumes a fixed structural relationships overtime which is problematic to assume among institutionally and technologically evolving restructured electricity markets. Thus, time varying long-run spot price relationships have been studied based on differing techniques such as fractional cointegration (Menezes and Houllier, 2014); state-space models based on Kalman filter algorithm (Zachmann, 2008; Nepal and Foster, 2016); network theory of interconnectedness (Castagneto-Gissey; Chaves and Fellani, 2014) and time varying price convergence tests based on Phillips and Sul $(2007,2009)$ as in Apergis et al. (2017a).

Previous studies have not considered the dynamics of volatility connectedness in electricity markets which is a prerequisite for evaluation of the progress towards higher levels of wholesale electricity markets integration. Further, studies of volatility connectedness in electricity markets are relatively few compared to the extensive literature on volatility connectedness across energy or energy commodity markets (Apergis et al., 2017b). In physically interconnected electricity markets, analysis of volatility connectedness uncovers 
information transmission mechanisms, and therefore, facilitates our understandings of information efficiency. Information efficiency predicts the ability of the market to respond to available information and incorporate it into the prices (Growtisch et al., 2015). Hence, the study of volatility connectedness can help forecasting price volatility and measure the market risk level providing a guide on the dynamics and efficiency of wholesale electricity pricing among interconnected electricity markets.

The notion of risk is of great relevance to electricity markets because they are more volatile than most commodity markets due to short-run demand and supply shocks resulting in price spikes given limited reserve capacities and transmission constraints. Managing and monitoring extreme market risks are important for financial risk management in wholesale electricity markets. The findings on volatility connectedness also further allows the the study of the differences in volatility across interconnected electricity markets and documents whether price volatility across those markets is high and (or) persistent either in wholesale electricity markets (Apergis et al., 2017b). Thus, the literature on the volatility connectedness in electricity markets is emerging and our study contributes to such emergence (Worthington et al., 2005; Higgs, 2009; Pen and Sevi, 2010; Bauwens et al. 2013; Pantos et al., 2019).

\section{Methodology}

\subsection{Construction of "good" and "bad" volatilities}

Andersen et al. (2001, 2003) and Barndorff-Nielsen (2002) proposed a novel approach to construct realized volatility ( $\mathrm{RV}$, hereafter) non-parametrically using intra-day prices. To further distinguish the upside versus downside variation, Barndorff-Nielsen et al. (2010) introduce the realized semivariance that is decomposed from the RV according to the positive and negative changes in asset prices. Segal et al. (2015) and Patton and Sheppard (2015) initiate 
the concepts of semivariance in empirical studies on financial markets and support the notion of "good" and "bad" volatilities, which correspond to positive and negative realized semivariances, respectively. Apergis et al. (2017b) has facilitated these concepts in their examination of the Australian electricity market.

Following Andersen et al. (2001, 2003), Barndorff-Nielsen (2002), Barndorff-Nielsen et al. (2010) and Segal et al. (2015), we construct the daily RV as well as its two components, the daily good volatilities $\left(R V^{+}\right.$, that is positive realized semivariance), and the daily bad volatilities $\left(R V^{-}\right.$, or negative realized semivariance) from the intra-day price changes as follows,

$$
\begin{aligned}
& R V_{m, t}=\sqrt{\sum_{i=1}^{N} r_{i, m, t}^{2}} \\
& R V_{m, t}^{+}=\sqrt{\sum_{i=1}^{N} \boldsymbol{I}_{\left(r_{i, m, t} \geq 0\right)} r_{i, m, t}^{2}} \\
& R V_{m, t}^{-}=\sqrt{\sum_{i=1}^{N} \boldsymbol{I}_{\left(r_{i, m, t}<0\right)} r_{i, m, t}^{2}}
\end{aligned}
$$

where $r_{i, m, t}$ is the difference between the $i$ th and the (i-1) intra-day logged price of electricity market $m$ in day $t$, which is, $r_{i, m, t}=\log \left(P_{i, m, t}\right)-\log \left(P_{i-1, m, t}\right) . N$ is the number of intra-day logged price changes in a day. $\boldsymbol{I}_{(f)}$ is an indicator function, getting value of 1 if the logical function $f$ is correct and 0 otherwise. We apply the square root to all three measures to convert them to the standard deviation of the return distribution, which are in percentage term.

We subsequently transform the volatilities into their natural logarithm before modelling to relax the non-negativity condition. Previous studies support the logarithm transformation of 
the volatilities in modelling in terms of model performance and application (e.g., Andersen et al., 2001; 2003; Corsi, 2009; and Corsi et al., 2010).

\subsection{Generalized connectedness index in a fractionally integrated VAR model}

\subsubsection{Symmetric connectedness measure}

We employ the generalized connectedness index proposed by Diebold and Yilmaz (2012) to assess the symmetric volatility connectedness between the Great Britain and the SEM. The advantage of the generalized approach compared to the orthogonalized approach is that the former provides a unique result regardless of the variable ordering in a multivariate system. In other words, by using the generalized method we do not need to assume the direction of the contemporaneous causality between the Great Britain's and SEM's volatilities. In addition, we follow Do et al. (2014) and Yip et al. (2017) to construct the generalized connectedness index within a fractionally integrated Vector Autoregressive (FIVAR) model. ${ }^{7}$ A utilization of the FIVAR model allows us to capture an important behaviour of the volatility, the long-range dependency, documented in energy markets including electricity market (e.g., Ma et al., 2017; Gong and Lin, 217; and Qu et al., 2018).

We construct three types of volatility connectedness indices including the total volatility connectedness among all markets, the directional volatility connectedness from one market to another market and the net volatility connectedness of a market. Intuitively, the total connectedness summarizes the contributions of shocks to all markets to the total variance forecasting errors of the whole system. The directional connectedness shows the contribution of a shock to one market to the variance forecasting errors in another market. Finally, the net connectedness is the difference between the directional connectedness "from" and "to" a

\footnotetext{
${ }^{7}$ The FIVAR framework, as a subset of the Vector Autoregressive Fractionally Integrated Moving Average (VARFIMA) model, was first studied by Sowell (1989) and has been significantly examined and used in the literature (e.g., Luceno, 1996; Martin and Wilkins, 1999; Andersen et al., 2003; Johansen, 2008; Sela and Hurvich, 2009; Chiriac and Voev, 2011; Do et al., 2014; Yip et al., 2017).
} 
specific market. We document the detail methodology and include the source for implemented program for calculation in the Appendix.

\subsubsection{Asymmetric connectedness measure}

To measure the asymmetric connectedness, we follow Barunik et al. (2015), Barunik et al. (2016) and Apergis et al. (2017a) by constructing the total connectedness and directional connectedness from market $i$ to market $j$ via good volatility (denoted as $S^{+}(H)$ and $S_{i \rightarrow j}^{+}(H)$, respectively) and via bad volatility (denoted as $S^{-}(H)$ and $S_{i \rightarrow j}^{-}(H)$, respectively) at the first instance. The connectedness via good (bad) volatility is constructed by replacing $R V_{t}$ in Eq. (7) with $R V_{t}^{+}\left(R V_{t}^{-}\right)$.

We subsequently define the total asymmetric volatility connectedness (TAC) as:

$$
T A C=100 \times \frac{S^{+}(H)-S^{-}(H)}{\frac{1}{2}\left(S^{+}(H)+S^{-}(H)\right)}
$$

The directional asymmetric volatility connectedness (DAC) from market $i$ to $j$ is defined as:

$$
D A C_{i \rightarrow j}=100 \times \frac{S_{i \rightarrow j}^{+}(H)-S_{i \rightarrow j}^{-}(H)}{\frac{1}{2}\left(S_{i \rightarrow j}^{+}(H)+S_{i \rightarrow j}^{-}(H)\right)}
$$

\section{Data}

The all-island market for wholesale electricity, comprising both the Republic of Ireland and Northern Ireland, started operation on 1 November 2007 while the wholesale electricity market is operated within the BETTA (British Electricity Trading and Transmission Arrangements) in Great Britain which includes England, Wales and Scotland. BETTA was created in 2005 when Scotland joined NETA (New Electricity Trading Arrangements) which in turn replaced the pool arrangement that existed prior to 2001. BETTA does not set unique 
system marginal price based on a pool system as in SEM where generators bid short-run marginal costs. However, the specific arrangements of the British market and model allows us to abstract a system marginal price as in SEM following Malaguzzi Valeri (2009). Half hourly electricity spot prices for BETTA from October 2009-October 2013 was obtained from ELEXON while day-ahead hourly spot prices data from November 2013 - October 2018 was sourced from Nord Pool UK. For the Irish market, half-hourly spot prices from October 2009October 2018 was obtained from the Single Electricity Market Operator (SEMO). To ensure consistency in our analysis, we converted half hourly prices into hourly prices and used these and inputs to calculate the intraday logged price changes of the electricity market. The intraday logged price changes are then employed to construct the daily RV and its two components $R V^{+}$and $R V^{-}$as formulated in $\mathrm{Eq}(1)-(3)$.

The Irish electricity price only includes energy-only price as the market operates separate prices for capacity remuneration. The GB price reflect a single product with no explicit separation of energy and capacity payments. The SEM operates mandatory physical pool based around single ex-post price while multiple forward and spot markets with voluntary participation is prevalent in other EU electricity markets like the UK. Nepal and Jamasb (2012) includes a detailed overview on the differences underlying the SEM and other mature European electricity markets. The Nordic power exchange, Nord Pool Spot, took over the short-term physical market clearing and operations of the British power exchange (N2EX, formed in January 2010) since 2013. Nord Pool Spot is the largest joint spot market for electrical energy in the world and organizes a day-ahead spot market via Elspot. Nord Pool Spot operates Europe's most mature power markets in Denmark, Sweden, Norway and Finland, as well as the Baltic region and is playing a key role in developing a trading platform designed to be harmonised with European cross-border intraday developments. 
We present the descriptive statistics for the $\mathrm{RV}, R V^{-}$and $R V^{+}$in Table 1. As noted in section 3 , we take the natural logarithm of volatility measures to avoid the non-negativity condition in volatility modelling. Overall, we find that the average level of volatility in the SEM is greater than in the Great Britain market. For both markets, we find that mean and the median of the logged volatilities are very close to each other indicating their near symmetric distributions. This is also confirmed by their skewness statistics, which are close to zero. The Jarque-Bera (J-B) tests statistically reject the null hypothesis of normal distribution of the logged volatilities. However, the low J-B test statistics and close-to-zero excess kurtosis of the logged volatilities indicate that their distribution is close to the normal distribution. This supports the use of natural log transformation of the volatilities before modelling.

Table 1: Summary statistics

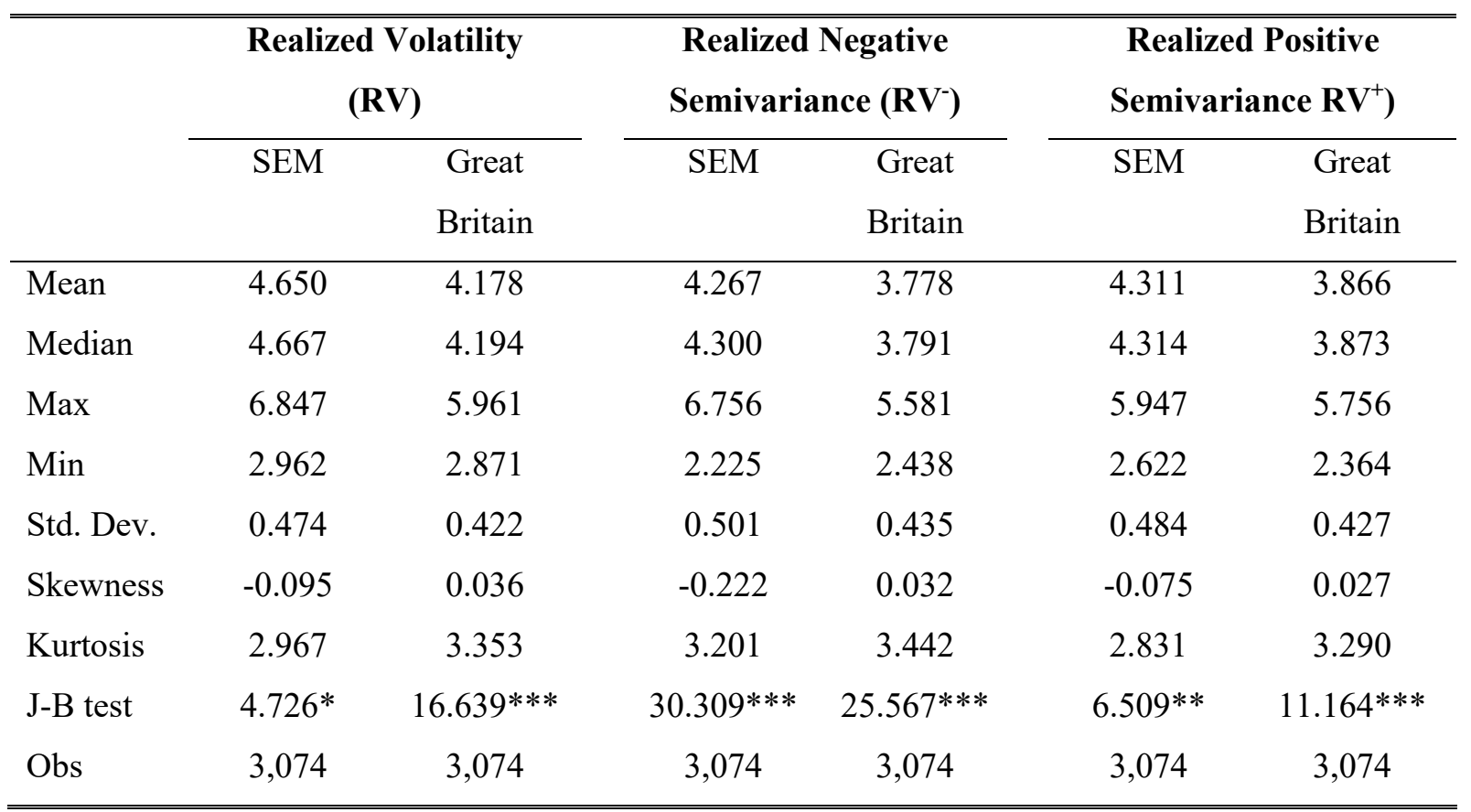

Note: J-B test indicates the Jarque-Bera test with a null hypothesis of the normal distribution. ${ }^{* * *},{ }^{* *}$ and $*$ denote that the null hypothesis is rejected at $1 \%, 5 \%$ and $10 \%$ level, respectively.

We further confirm the long memory behaviour of volatilities with previous studies in electricity market (e.g., Qu et al., 2018) by estimating the fractional degrees of the RV and its two components, $R V^{-}$and $R V^{+}$, using Shimotsu (2007) approach. As seen from Table 2, the 
estimated fractional degrees of all volatilities for the two markets are statistically and significantly different from 0 but well below 1 , indicating the long-memory characteristics. This statistical evidence supports our choice of FIVAR framework in modelling the interdependency between the volatilities of the Irish and Great Britain electricity markets.

Table 2: Fractional degrees of realized volatility and realized semivariance

\begin{tabular}{lccc}
\hline \hline & $\begin{array}{c}\text { Realized Volatility } \\
(\mathbf{R V})\end{array}$ & $\begin{array}{c}\text { Realized Negative } \\
\text { Semivariance }\left(\mathbf{R V}^{-}\right)\end{array}$ & $\begin{array}{c}\text { Realized Positive Semivariance } \\
\left(\mathbf{R V}^{+}\right)\end{array}$ \\
\hline Great Britain & $0.58^{* * *}$ & $0.57^{* * *}$ & $0.59^{* * *}$ \\
& $(67.30)$ & $(65.45)$ & $(68.48)$ \\
SEM & $0.47^{* * *}$ & $0.46^{* * *}$ & $0.48^{* * *}$ \\
& $(54.70)$ & $(52.56)$ & $(56.14)$ \\
\hline
\end{tabular}

Note: We employ Shimotsu (2007) to estimate the long memory degree of the volatilities with associated $t$ statistics reported in brackets. $* * * * *$, and $*$ denote the memory degrees are statistically and significantly different from 0 at $1 \%, 5 \%$ and $10 \%$ level, respectively.

\section{Empirical Results}

This section discusses the volatility connectedness and asymmetries between Great Britain and SEM. We first construct the static volatility connectedness indices (both symmetric and asymmetric) over the whole sample using the 10-day ahead FEVD. Subsequently, we estimate the dynamic volatility connectedness (both symmetric and asymmetric) indices using a moving window of 200 days and 10-day ahead FEVD. ${ }^{8}$

\subsection{Static (unconditional) volatility connectedness between Great Britain and Ireland}

\section{electricity market}

We present the static (unconditional) connectedness between the two electricity markets via their realized volatility, good and bad volatility over the period between 2009 and 2018 in Table 3.

\footnotetext{
${ }^{8}$ We have also performed robustness checks with different choices of window size (including 150 and 250 days) and forecasting horizon (including 5- and 7-day ahead). Our main results remain consistent.
} 
Table 3: Overall connectedness (\%) of markets via each moment: Rows (From), Columns (To)

\begin{tabular}{|c|c|c|c|}
\hline & To Great Britain & To SEM & To others \\
\hline \multicolumn{4}{|c|}{ Panel A: Realized Volatility } \\
\hline From Great Britain & 93.37 & 4.07 & 4.07 \\
\hline From SEM & 5.48 & 97.12 & 5.48 \\
\hline From others & 5.48 & 4.07 & Total \\
\hline Net connectedness & -1.41 & 1.41 & 4.77 \\
\hline \multicolumn{4}{|c|}{ Panel B: Realized negative semivariance (bad volatility) } \\
\hline From Great Britain & 95.35 & 2.69 & 2.69 \\
\hline From SEM & 3.73 & 98.24 & 3.73 \\
\hline From others & 3.73 & 2.69 & Total \\
\hline Net connectedness & -1.05 & 1.05 & 3.21 \\
\hline \multicolumn{4}{|c|}{ Panel C: Realized positive semivariance (good volatility) } \\
\hline From Great Britain & 93.11 & 4.55 & 4.55 \\
\hline From SEM & 5.85 & 96.51 & 5.85 \\
\hline From others & 5.85 & 4.55 & Total \\
\hline Net connectedness & -1.30 & 1.30 & 5.20 \\
\hline
\end{tabular}

Note: This table summarises the volatility connectedness between the Great Britain and Irish electricity markets. The row "From others" summarises the directional connectedness from all other states to one state. The column "To others" summarises the directional connectedness from one state to all other states. The cell "Total" shows the total connectedness between two states via each volatility measures. Other columns show the pairwise directional connectedness between two relevant states.

As seen from Table 3, we find that the unconditional volatility connectedness between the Great Britain and SEM over the $2009-2018$ period is $4.77 \%$. The low volatility of connectedness is explained by the inefficient flows across the two interconnectors between Britain and the SEM up until 1 October 2018 when market coupling took place (Newbery et al., 2019). In the long-term, a major part of volatilities of Great Britain and SEM are connected within their domestic market (around 95\%) on average rather than cross-border connectedness. Over this ten-year period, Great Britain is the net receiver while SEM is the net transmitter of the connectedness. We attribute this result to several factors. First, electricity generation in the UK has been declining since 2005 which includes during, before and after the 2008 global 
financial crisis with per capita electricity generation falling by $24 \%$ since 2005 . Second, UK renewable generation has increased by $95 \mathrm{TWh}$ since 2005 . UK's electricity generation is characterised by a strong decline of coal (since 2012) but the rise of wind, biomass and solar since 2009 (the starting period of our analysis). Third, whereas interconnector flows before GB introduced the carbon price support in 2013 were mostly from GB to the SEM; they are often in the opposite direction, despite the SEM having higher cost plant and greater carbon intensity (Newbery et al. 2019). The GB carbon tax since 2013 has reversed the direction of GB-SEM trade (see figure in in Appendix). However, there is a general downward trend in the UK wholesale electricity price from 2013 mainly driven by decrease in gas prices and increase in the amount of electricity generated from renewable technologies.

Assessing the volatility connectedness from the perspective of good (volatilities associated with positive returns) and bad (volatilities associated with negative returns), we find that the good volatility connectedness dominates the bad volatility connectedness on average over the 10-year-period under examination. Therefore, the volatility connectedness between Great Britain and SEM tends to be mainly and unconditionally driven by the good volatility. This result is explained by the growing similarity in these two markets mostly in the form of convergence of generation technologies. SEM has an ambitious target of achieving $40 \%$ of electricity consumed from renewable sources by 2020 . The introduction of the carbon price support in the UK in 2013 has meant that the price of carbon dioxide permits has increased to the point where it is penalizing coal generation that is relatively more abundant in Great Britain and hence the two markets become more similar as also anticipated in an earlier finding by Malaguzzi-Valeri (2009). The differences in generation technologies in these two markets has meant that the market integration benefits are being achieved even when the size of interconnector capacities and interconnector flows is low between these two physically interconnected markets. 


\subsection{Dynamic (conditional) volatility connectedness between Great Britain and SEM}

The static volatility connectedness analysis discussed above shows a broad picture about the average or unconditional aspect of the volatility connectedness between the two markets over the whole analysed period. However, by construction it does not provide any information about the dynamic side of the volatility connectedness, which is highly conditional on the policy changes and/or significant events such as Brexit. In this subsection, therefore, we complete the detail picture of the volatility connectedness between Great Britain and SEM by analysing its dynamic (or conditional) aspect.

\subsubsection{Conditionally symmetric volatility connectedness}

We present the total dynamic volatility connectedness between the two considered markets in Fig. 1.

As seen from the figure, the volatility connectedness between the two markets is time varying, with its troughs (peaks) of around 2\% (12\%). Even though the static analysis described in Table 3 shows a low unconditional volatility connectedness between the two markets on average (around 5\%), the dynamic analysis shows that at some particular points in time, the conditional volatility linkages between the two markets can be significant at $12 \%$, which is more than double the unconditional level.

There are notable periods when the volatility connectedness between the two markets remains at a relatively high level, including the early 2011 - mid 2012 of around 8\%, mid 2015 - mid 2016 of around 12\%, and mid 2016 of nearly 8\%. These shifts are conditional on significant policy changes and events, which may cause significant dynamics in Great Britain and/or SEM. 
Fig. 1: Total volatility connectedness (\%) between Great Britain and SEM

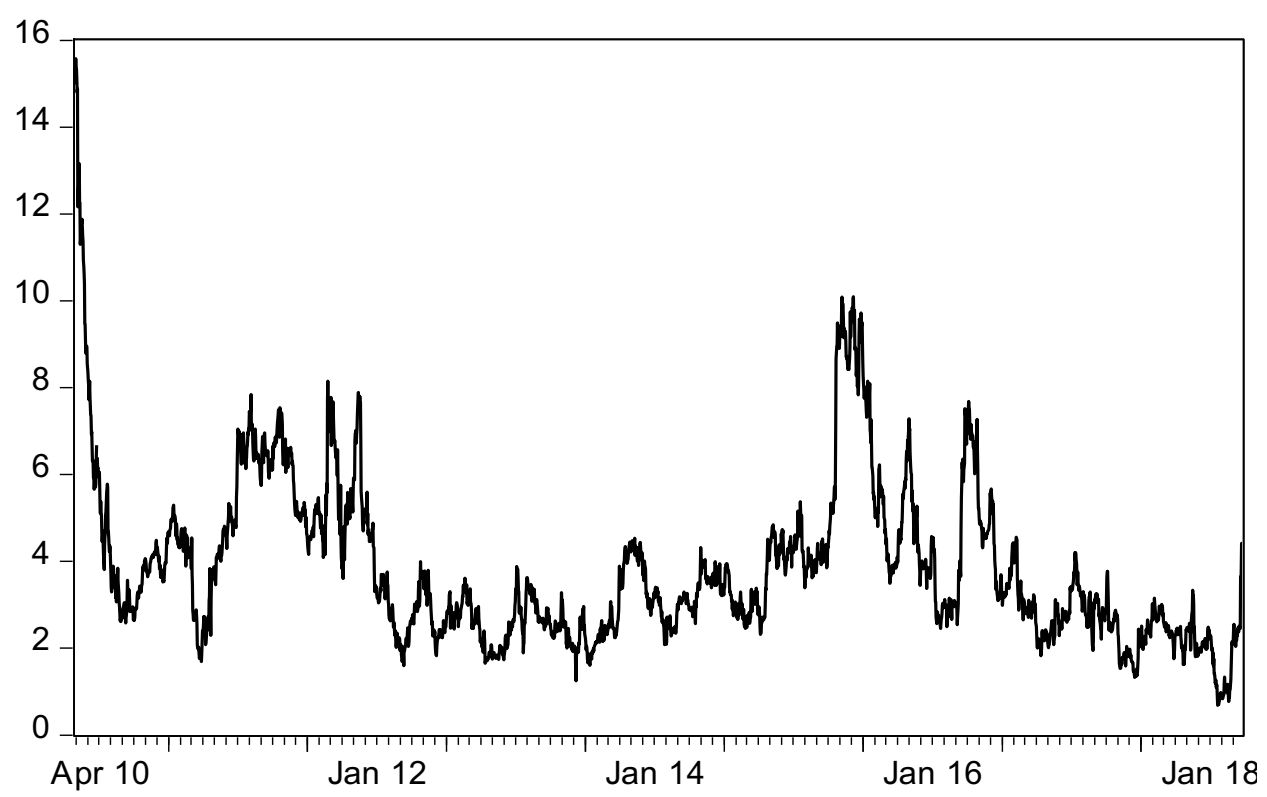

Note: This figure shows dynamic (conditional) total volatility connectedness (in percentage) between the Great Britain and SEM. This index is constructed using Eq. (7) under a FIVAR model of RV with a moving window of 200 days and 10-day ahead FEVD.

To further investigate which events and/or policy changes contribute to remarkable periods discussed earlier, we examine in more detail about the contribution of connectedness from each market. Fig. 2 displays the connectedness contributed by Great Britain, by SEM and the net connectedness from SEM. It is noteworthy that as our system only includes Great Britain and SEM, the positive range observed in the net connectedness from SEM shows that total connectedness is mainly driven by SEM, while the negative range illustrates Great Britain is the main driver of the total connectedness.

As illustrated in Fig. 2, we find that the early 2011 - mid 2012 period, and the end of 2015 - early 2016 period of high volatility connectedness between the two markets is mainly driven by volatility connectedness contribution from SEM. This suggests dynamics in SEM markets played a major role in connecting the volatilities between the two markets during these periods. Regarding the first period, in 2011, the electricity efficiency in SEM increased 
significantly from $44.6 \%$ to $47.3 \%$ due to the full operations of Combined Cycle Gas Turbine powers as well as increased contribution from wind and hydro. However, the year 2012 had witnessed a different trend in the SEM where more coal was being used in generation due to relatively high gas price in a companion with low prices of coal. This had decreased the efficiency in SEM considerably to $45.6 \%$ in $2012 .{ }^{9}$ For the mid 2015 - mid 2016 period, the Irish electricity market experienced fluctuations through the talks and signings on the market re-design together with the 'Brexit' movement in the UK.

Fig. 2: Directional and net connectedness (\%) from Great Britain and SEM
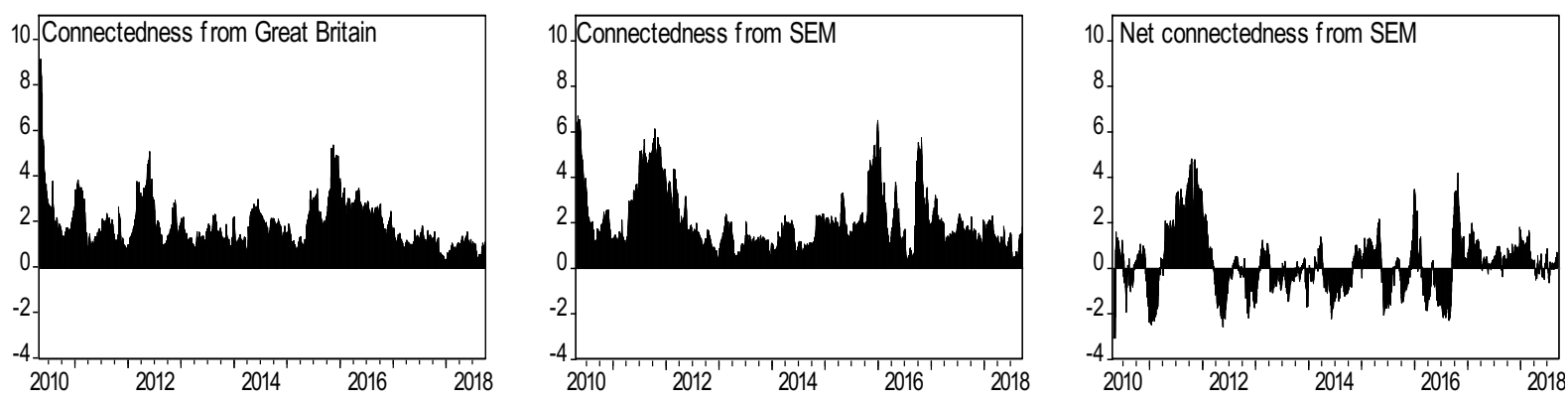

Note: This figure shows dynamic (conditional) directional and net volatility connectedness (in percentage) between the Great Britain and SEM. These indices are constructed using Eq. (8) and (9) respectively under a FIVAR model of RV with a moving window of 200 days and 10-day ahead FEVD.

The high-level market redesign of the 'Single Electricity Market' into an 'Integrated Single Electricity Market (I-SEM)' was proposed as early as in September, 2014. The Integrated Single Electricity Market is a new wholesale market for Ireland and Northern Ireland since 1 October 2018 and promotes free flow of energy across borders by integrating the allisland and European electricity markets as per the requirements of the EU Target Model. One of the major features of the I-SEM is the move away from its current mandatory pool to a voluntary bilateral trading model based on the European target model alongside the

\footnotetext{
${ }^{9}$ We extract these figures from SEAI (2017).
} 
introduction of day-ahead, intraday and forward markets as well as radical changes to the capacity payment mechanisms. However, the discussions and move to ISEM coincided with the Brexit for which a referendum in the UK occurred during June 2016.

Therefore, as the third remarkable period of the volatility connectedness between the two markets, middle of 2016, Fig. 2 shows a dominance of the volatility connectedness from Great Britain to SEM. This is illustrated more clearly through the negative range of the net volatility connectedness from SEM between the middle and end of 2016. In fact, this result can be attributed to an initiation of Brexit, the event that leads to exit of UK from the European Union (EU). In June 2016, a referendum held by the UK regarding its EU membership was concluded with a majority (51.9\%) voting to leave EU. This caused uncertainties in both aspects, (i) electricity prices in these two bilateral markets and, (ii) the outlook for "a more integrated, open and efficient pan-European electricity market" that Irish market aimed at that time (Wallace, 2019). Brexit has the potential to impact the governance of the all island electricity market as well as the future supply security of Ireland since the Irish-British relations is an integral feature of the negotiations surrounding Brexit.

The increases in electricity price volatilities caused by Brexit were mainly through the channel of exchange rate fluctuations. The Great Britain market enjoys cheaper electricity via four cross-border interconnectors, especially from the interconnection with France and the Netherlands. Under the effect of 2016 Brexit referendum, ${ }^{10}$ GBP depreciated by $15 \%$ against Euro and the USD, which caused an immediate impact on the input costs, and in turn, led to a $50 \%$ increase in the Great Britain electricity price volatility (see Gissey et al., 2018).

In another aspect, the 2016 Brexit referendum caused uncertainties in the outlook for a more integrated SEM as mentioned earlier. This outlook was rooted since 2011, when EirGrid,

\footnotetext{
${ }^{10}$ This referendum is also called as the $2016 \mathrm{EU}$ referendum. However, we use the term Brexit referendum in this paper to emphasize on the effect of the initiation of the Brexit.
} 
a state-owned electric power transmission operator in SEM, launched the so-called DS3 program $^{11}$ as a direct response to not only national but also European energy policies and targets. It was expected that when completed, the SEM's operations would be integrated with other western European electricity markets, which was recently effective in October 2018 as Integrated-SEM (or I-SEM) (see Dutton, 2016).

\subsubsection{Conditionally asymmetric volatility connectedness}

In this section, we discuss the asymmetric aspect of the conditional volatility connectedness between the Great Britain electricity market and SEM. In additional to the symmetric analyses discussed in previous section, the asymmetric analyses complete the picture by depicting how the upside (via good volatility) and/or downside (via bad volatility) risk is conditionally connected. In other word, we examine how the time-varying behaviour of good and bad volatility connectedness is conditional on events and/or policy changes in the two markets. More importantly, we investigate how the difference between good and bad volatility connectedness is driven.

We present the total good and bad volatility connectedness between Great Britain and SEM as well as its total asymmetric volatility connectedness in Fig. 3. The figure shows that information transmission dominated by good and bad volatility has been interchanged over the 8-year period. In terms of magnitude, the dominance of good volatility connectedness is slightly larger than that of the bad volatility connectedness in general (see first graph). Meanwhile, we observe a higher frequency that the volatility connectedness switches to the regime dominated by the bad volatility connectedness compared to the reserve direction. Consistently, the duration of the TAC staying in the regime of bad volatility dominated connectedness is longer than that of good volatility dominated connectedness. Particularly, we note three interesting periods of the asymmetric volatility connectedness including, 2013-2015,

\footnotetext{
${ }^{11}$ DS3 is named in its spirit of "Delivering a Secure, Sustainable Electricity System".
} 
March - 2015 to middle of 2016, and middle of 2016 to around end of 2017 periods. While the first and third periods are dominated by bad volatility connectedness (i.e., volatility connectedness driven by negative returns), the second period is dominated by good volatility connectedness (or volatility connectedness driven by positive returns).

Fig. 3: Total asymmetric connectedness (\%) between Great Britain electricity market and SEM

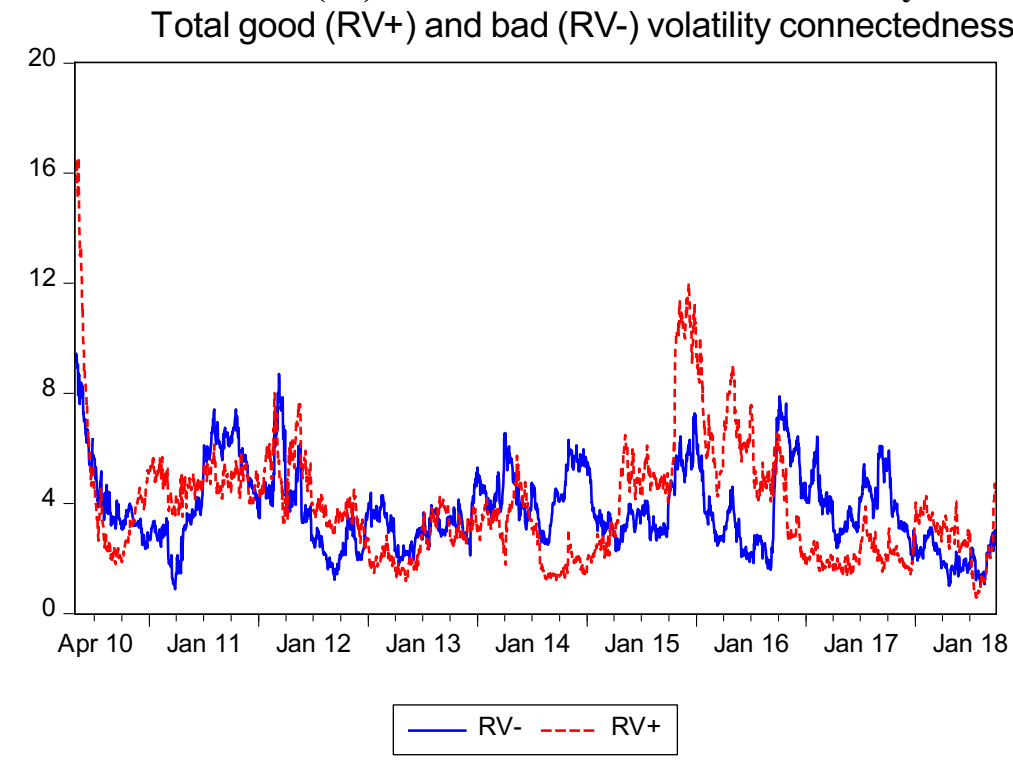

Total Asymmetric Connectedness (TAC)

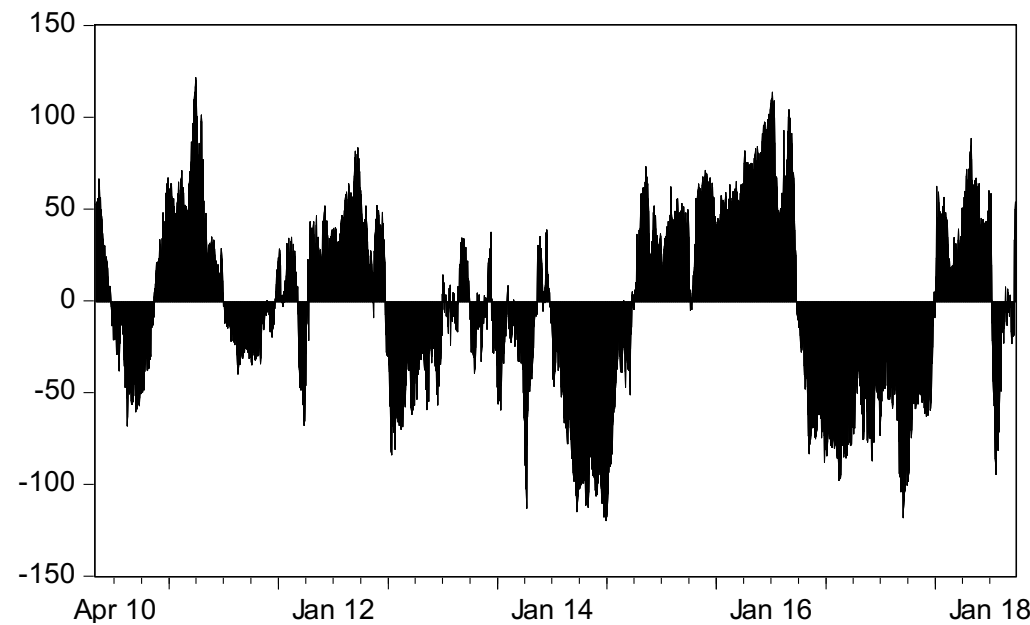

Note: The first graph shows the bad volatility (RV-) and the good volatility $(\mathrm{RV}+)$ connectedness between the two markets. The second graph shows the total asymmetric volatility connectedness (TAC) between the two markets, in which the positive (negative) range illustrates the dominance of the good (bad) volatility. The indices are constructed using a moving window of 200 days and 10-day ahead FEVD. 
We look for more details about the contribution of each market to the asymmetric dynamics of the volatility connectedness regarding these three remarkable periods by investigating the directional asymmetric volatility connectedness between Great Britain and SEM (see Fig. 4).

Fig. 4: Directional asymmetric volatility connectedness between Great Britain market and SEM

Good volatility $(\mathrm{RV}+)$ connectedness from Great Britain
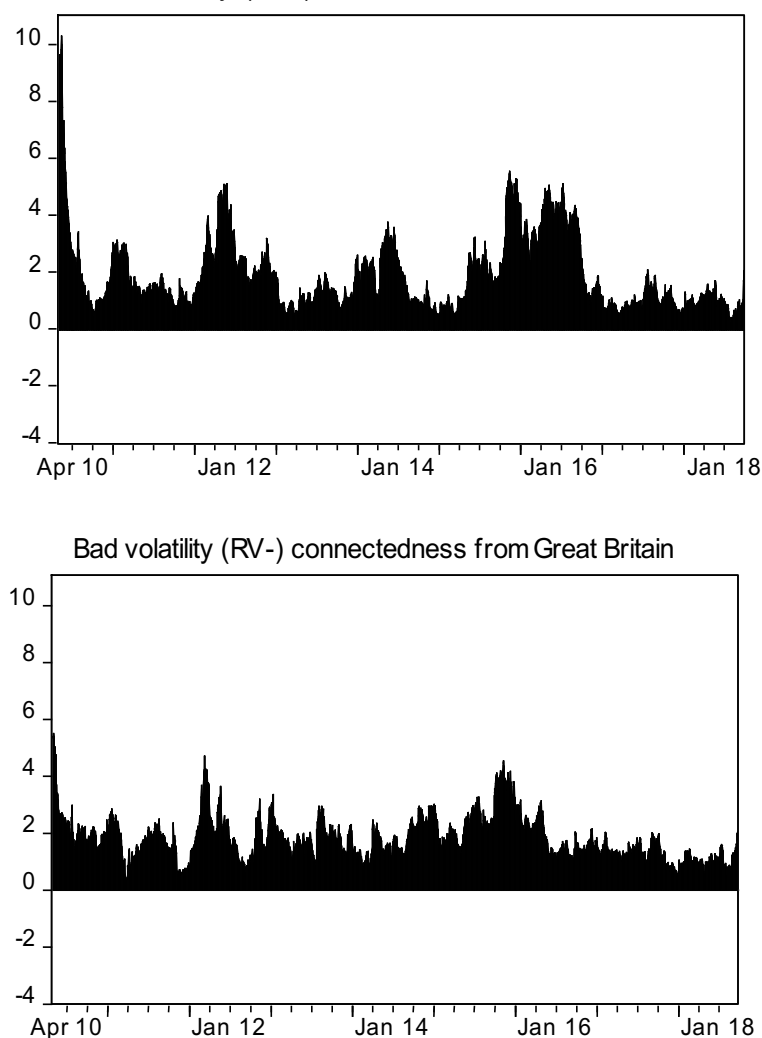

150 Directional Asymmetric Connectedness (DAC) from Great Britain

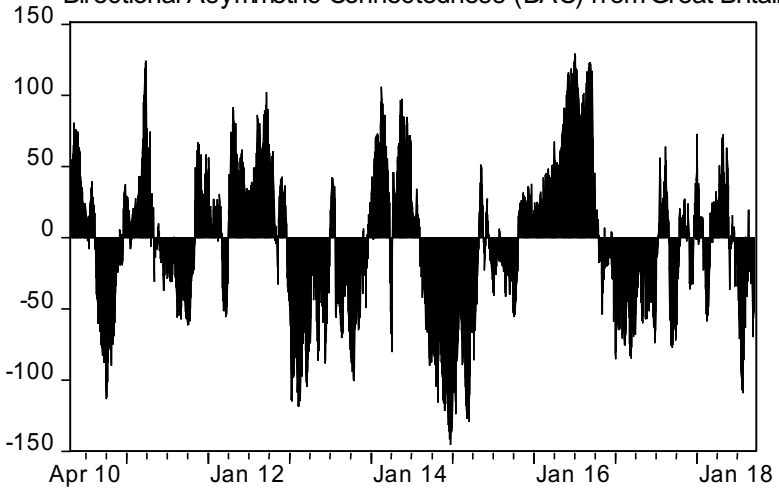

Good Volatility $(\mathrm{RV}+)$ connectedness from SEM
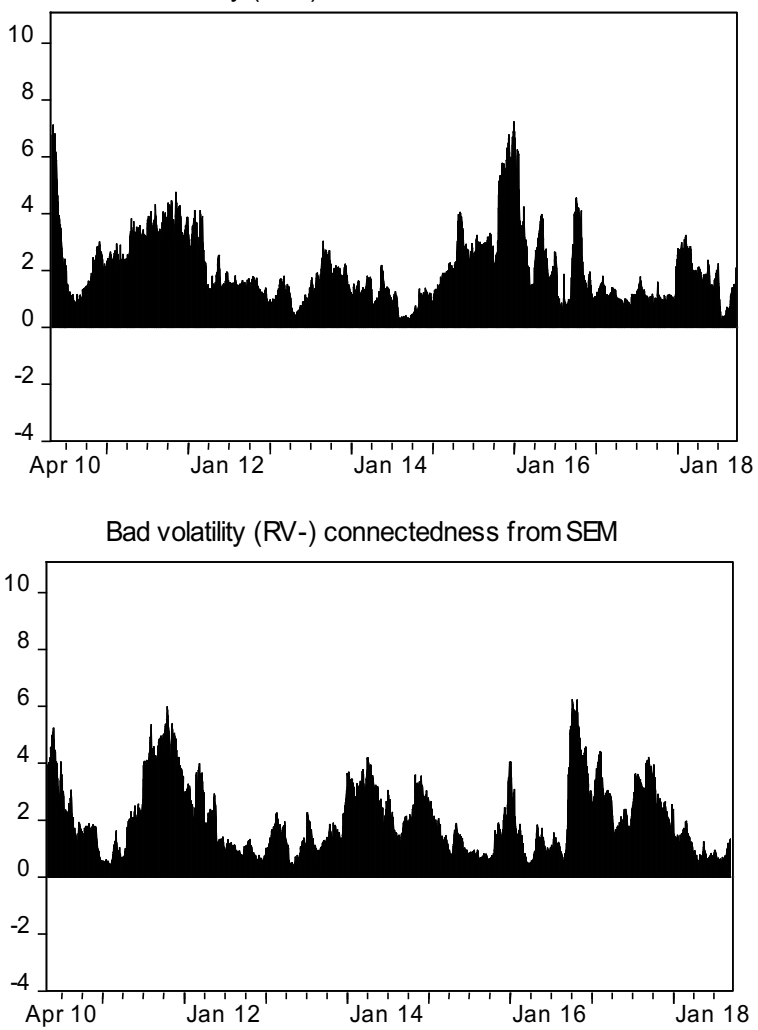

Directional Asymmetric Connectedness (DAC) from SEM

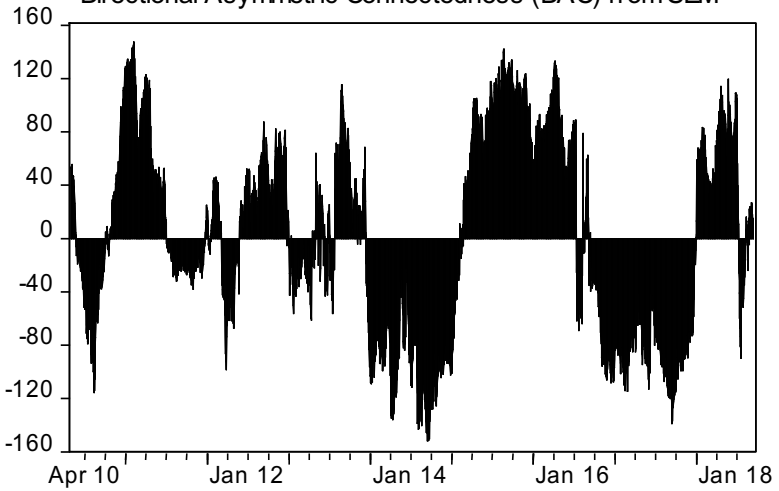

Note: This figure shows dynamic (conditional) directional good ( $1^{\text {st }}$ row $)$, bad ( $2^{\text {nd }}$ row $)$, and asymmetric ( $3^{\text {rd }}$ row $)$ volatility connectedness between the Great Britain and SEM. These indices are constructed using a moving window of 200 days and 10-day ahead FEVD. 
We find that during 2013-2015, Great Britain electricity market played a leading role by contributing to the dominance of the bad volatility connectedness between 2013 and 2014 while the SEM was the main contributor to this behaviour between 2014 and 2015. The 20132014 period that negative returns drove volatility connectedness in the Great Britain market was due to a combination of factors, including a high gas price pass-through rates (around $100 \%$, indicating a near perfect cost-reflectivity), a large fraction of the time gas plants set the wholesale price (nearly 60\%) ${ }^{12}$, a decreasing trend of gas price (Gissey et al., 2018), and an appreciation trend of British pound against euro for most of 2013-2014 period.

The gas-related factors contributed to the decreasing trend of the price through domestic electricity generation, while the exchange rate channel caused a decreasing cost for electricity that Great Britain imported through interconnectors with other European countries. Regarding the Irish electricity market, the 2014-2015 period of volatility connectedness driven by negative returns was mostly due to a sharp decrease in the global oil price from around USD110 per barrel to around USD50 per barrel.

As for the period between March 2015 and mid-2016, the overall dominance of the good volatility connectedness was mainly driven by the Irish market. This is possibly due to forums and signings regarding the I-SEM market re-designs that coincided with the Brexit movement in the UK. The DAC analysis shown in Fig. 4 indicates that a period of negative returns-driven volatility connectedness spanning from middle of 2016 to around end of 2017 between the two markets is dominated by the Irish market. This is consistent with the depreciation of the GBP against EUR following the 2016 Brexit referendum in combination with relatively stable oil price.

\footnotetext{
12 This is also known as "shares at the margin of gas" (see Gissey et al., 2018).
} 


\section{Conclusions}

This paper studies the volatility connectedness between the Great Britain and Irish wholesale electricity markets from different aspects including static (unconditional) vs dynamic (conditional) and symmetric vs asymmetric analyses. We find that the volatility connectedness between the two markets are unconditionally low (around 5\%) over the 20092018 period. However, the volatility connectedness has been significantly altered conditional by important events, policy reforms or market re-designs such as Brexit, oil price slump, increasing share of renewables, and fluctuations in the exchange rates. These remarkable changes when absorbed by the markets could boost the volatility connectedness more than double than its unconditional level.

Additionally, through asymmetric analysis, we find that the magnitude of good volatility dominated connectedness is slightly larger than that of the bad volatility dominated connectedness over the 8-year period from 2010 to 2018 . This is attributed to the growing similarity of the markets in energy generation driven by the surge of renewable electricity. Our results suggest that good volatility levels would be even higher once the Irish market adopts the carbon price floor. Thus, supporting renewable generation by setting an appropriate price of carbon in interconnected wholesale electricity markets will improve market integration. We also observe frequent interchanges regarding dominant role of good and bad volatility in driving the volatility connectedness, due to the changes in the leading role of each market in originating this interrelationship.

Future research can focus on the dynamics of volatility connectedness between these two markets after the introduction of I-SEM as longer time series data becomes available together with the adoption of a carbon price support in the I-SEM which we advocate to between integrate these two physically interconnected markets. 


\section{Appendix: Construction of the generalized connectedness indices following Diebold and Yilmaz $(2012,2014)$ approach.}

Our generalized connectedness indices at horizon $H$ are constructed based on the generalized forecast-error variance decomposition (FEVD) matrix at horizon $H$, whose element intersected between row $i$ th and column $j$ th is calculated as:

$$
F E V D_{i j}^{g}(H)=\frac{\sigma_{j j}^{-1} \sum_{h=0}^{H-1}\left(e_{i}^{\prime} \Lambda_{h} \Sigma_{\varepsilon} e_{j}\right)^{2}}{\sum_{h=0}^{H-1}\left(e_{i}^{\prime} \Lambda_{h} \Sigma_{\varepsilon} \Lambda_{h}^{\prime} e_{i}\right)}
$$

The FEVDs are obtained from a bivariate FIVAR system of Great Britain's and SEM's RV, $R V_{t}=\left(R V_{G, t}, R V_{I, t}\right)^{\prime}$, which is specified as,

$$
\left(I_{2}-\sum_{i=1}^{p} \Phi_{i} L^{i}\right) D(L) R V_{t}=\varepsilon_{t}
$$

where $\varepsilon_{t} \sim$ i.i.d. $\left(0, \Sigma_{\varepsilon}\right)$, and $\Sigma_{\varepsilon}=\left\{\sigma_{i j} ; i, j=1,2\right\} . \Phi_{i}$ is the $(2 \times 2)$ coefficient matrix associated with lag $i$ of $\mathrm{RV}$, and $I_{2}$ is the $(2 \times 2)$ identity matrix. $L$ is the lag operator and $p$ is the lag order of the lag polynomial, which is chosen based on the lowest Schwarz Information Criterion (SIC). $D(L)=\operatorname{diag}\left\{(1-L)^{d_{1}},(1-L)^{d_{2}}\right\}$ is a diagonal matrix of fractional degrees $(d)$, which captures the long memory behaviour of the volatilities of the two markets. We follow the two-step estimation approach described in Yip et al. (2017) to estimate our FIVAR system. $^{13}$

In Eq. (4), $\Lambda_{h}=\sum_{j=0}^{h} \Xi_{j}^{(d)} A_{h-j}$ with $\Lambda_{0}=I_{2}$ if $h=0 . \Xi_{j}^{(d)}$ is the diagonal $(2 \times 2)$ matrix with $\xi_{j}^{\left(d_{i}\right)}=\frac{\Gamma\left(j+d_{i}\right)}{\Gamma\left(d_{i}\right) \Gamma(j+1)}$ as the $i$ th diagonal element. $\mathrm{A}_{i}$ can be obtained recursively as, $\mathrm{A}_{i}=\sum_{j=1}^{p} \mathrm{~A}_{i-j} \Phi_{j}$ with $\mathrm{A}_{0}=I_{2}$. For other input of the Eq. (6), $e_{i}$ is a $(2 \times 1)$ vector whose $i$ th element is unity and zeros elsewhere.

\footnotetext{
${ }^{13}$ Interested readers can refer to Yip et al. (2017) for Matlab code in estimating the volatility connectedness within a FIVAR system., which is available at https://www.sciencedirect.com/science/article/pii/S0140988317302451\#s0060.
} 
We normalize each element of the FEVD matrix by its row sum, as follows:

$$
\widetilde{F E V D}_{i j}(H)=\frac{F E V D_{i j}(H)}{\sum_{j=1}^{2} F E V D_{i j}(H)}
$$

with $\sum_{j=1}^{2} \widetilde{F E V D}_{i j}(H)=1$ and $\sum_{i, j=1}^{2} \widetilde{F E V D}_{i j}(H)=2$ by construction.

Following Diebold and Yilmaz (2012), the total connectedness index describes the contribution of connectedness across both Great Britain's and SEM's RV to the total forecast error variance,

$$
S(H)=\frac{\sum_{i, j=1, i \neq j}^{2} \widehat{F E V D}_{i j}(H)}{2} \times 100
$$

In a bivariate system, the directional connectedness from a variable $i$ to a variable $j$ can be computed as:

$$
S_{i \rightarrow j}(H)=\frac{\sum_{i=1, i \neq j}^{2} \widehat{F E V D}_{j i}(H)}{2} \times 100
$$

Therefore, the net connectedness from a variable $i$ to variable $j$, which shows whether variable $i$ is a net transmitter or net receiver of connectedness, can be computed as

$$
S_{i}(H)=S_{i \rightarrow j}(H)-S_{i \leftarrow j}(H)
$$




\section{References}

Andersen, T., Bollerslev, T., and Diebold, F. (2003). Modeling and forecasting realized volatility. Econometrica, 71, 579-625.

Andersen, T., Bollerslev, T., Diebold, F., and Ebens, H. (2001). The distribution of realized stock return volatility. Journal of Financial Economics, 61, 43-76.

Apergis, N., Barunik, J., and Lau, C. (2017b). Good volatility, bad volatility: what drives the asymmetric connectedness of Australian electricity markets? Energy Economics, 66, 108-115.

Apergis, N., Fontini , F., and Inchaupse, J. (2017a). Integration of regional electricity markets in Australia: A price convergence assessment. Energy Economics, 62, 411-418.

Barndorff-Nielsen, O. (2002). Econometric analysis of realized volatility and its use in estimating stochastic volatility models. Journal of Royal Statistical Society: Series B, 64, 253-280.

Barndorff-Nielsen, O., Kinnebrock, S., and Shephard, N. (2010). Measuring downside riskrealized semivariance. In Volatility and Time Series Econometrics: Essays in Honor of Robert F. Engle. Oxford: Oxford University Press.

Barunik, J., Kocenda, E., and Vacha, L. (2015). Volatility spillovers across petroleum markets. Energy Journal, 36, 309-329.

Barunik, J., Kocenda, E., and Vacha, L. (2016). Asymmetric connectedness on the U.S. stock market: Bad and good volatility spillovers. Journal of Financial Markets, 27, 55-78.

Bauwens, L., Hafner, C., and Pierret, D. (2013). Multivariate volatility modelling of electricity futures. Journal of Applied Econometrics, 28, 743-761.

Castagneto-Gissey, G., Chavez, M., and Di Vico Fellani, F. (2014). Dynamic Granger-Causal Networks of Electricity Spot Prices: A Novel Approach to Market Integration. Energy Economics, 44, 422-432.

Chang, C., McAleer, M., and Tansuchat, R. (2010). Analyzing and forecasting volatility spillovers, asymmetries and hedging in major oil markets. Energy Economics, 32, 1445-1455.

Chiriac, R., and Voev, V. (2011). Modelling and forecasting multivariate realized volatility. Journal of Applied Econometrics, 26, 922-947.

Corsi, F. (2009). A simple approximate long-memory model of realized volatility. Journal of Financial Econometrics, 7, 174-196.

Corsi, F., Pirino, D., and Reno, R. (2010). Threshold bipower variation and the impact of jumps on volatility forecasting. Journal of Econometrics, 159, 276-288.

De Vany, A., and Walls, W. (1999). Conintegration analysis of spot electricity prices: insights on transmission efficiency in the Western US. Energy Economics, 21, 435-448. 
Deane, P., FitzGerald, J., Valeri, L., Tuohy, A., and Walsh, D. (2015). Irish and British electricity prices: what recent history implies for future prices. Economics of Energy and Environmental Policy, 4, 1-15.

Dempster, G., Isaacs, J., and Smith, N. (2008). Price Discovery in Restructured Electricity Markets. Resource and Energy Economics, 30, 250-259.

Diebold, F. X., and Yilmaz, K. (2012). Better to give than to receive: predictive directional measurement of volatility spillovers. International Journal of Forecasting, 28, 57-66.

Do, H. X., Brooks, R., Treepongkaruna, S., and Wu, E. (2014). How does trading volume affect financial return distribution? International Review of Financial Analysis, 35, 190-206.

Dutton, J. (2016). The politics of cross-border electricity market interconnection: the UK, Ireland and Greenlink. UK Energy Research Centre.

European Commission. (2014). Progress towards completing the Internal Energy Market. Brussels: European Commission.

Ewing, B. T., and Malik, F. (2013). Volatility transmission between gold and oil futures under structural breaks. International Review of Economics and Finance, 25, 113-121.

Ferrer, R., Shahzad, S.J.H., Lopez, R. and Jareno, F. (2018). Time and Frequency Dynamics of Connectedness between Renewable Energy Stocks and Crude Oil Prices, Energy Economics, Vol. 76, pp.1-20.

Gissey, G. C., Grubb, M., Staffell, I., Agnolucci, P., and Ekins OBE, P. (2018). Wholesale cost reflectivity of $G B$ and European electricity prices. London: The Office of Gas and Electricity Markets (Ofgem).

Gong, X., and Lin, B. (2017). Forecasting the good and bad uncertainties of crude oil prices using HAR framework. Energy Economics, 67, 315-327.

Growitsch, C., Stronzik, M., and Nepal, R. (2015). Price Convergence and Information Efficiency in German Natural Gas Markets. German Economic Review, 16, 87-103.

Gugler, K., Haxhimusa, A., and Liebensteiner, M. (2018). Integration of European Electricity Markets: Evidence from Spot Prices. Energy Journal, 39. doi:10.5547/01956574.39.SI2.kgug

Higgs, H. (2009). Modelling Price and Volatility Inter-Relationships in the Australian Wholesale Spot Electricity Market. Energy Economics, 31, 748-756.

Johansen, S. (2008). A representation theory for a class of vector autoregressive models for fractional processes. Econometric Theory, 24, 651-676.

Joskow, P.L. (2019). Challenges for Wholesale Electricity Markets with Intermittent

Renewable Generation at Scale, Oxford Review of Economic Policy, Vol. 35 (2), pp. 291-331.

Luceno, A. (1996). A fast likelihood approximation for vector general linear processes with long series: Application to fractional differencing. Biometrika, 83, 603-614.

Ma, F., Wahab, M., Huang, D., and Xu, W. (2017). Forecasting the realized volatility of the oil futures market: a regime switching approach. Energy Economics, 67, 136-145. 
Malaguzzi Valeri, L. (2009). Welfare and Competion Effects of Electricity Interconnection between Ireland and Great Britain. Energy Policy, 37, 4679-4688.

Martin, V. L., and Wilkins, N. P. (1999). Indirect estimation of ARFIMA and VARFIMA models. Journal of Econometrics, 93, 149-175.

Menezes, L. D., and Houllier, M. (2016). Reassessing the integration of European electricity markets: a fractional cointegration analysis. Energy Economics, 53, 132-150.

Nepal, R., and Foster, J. (2016). Testing for market integration in the Australian national electricity market. Energy Journal, 37, 215-237.

Newbery, D., Gissey, G. C., Guo, B., and Dodds, P. E. (2019). The private and social value of British electrical interconnectors. University of Cambridge: Energy Policy Research Group.

Newbery, D., Strbac, G., and Viehoff, I. (2016). The Benefits of Integrating European Electricity Markets. Energy Policy, 94, 253-263.

Newbery, D.M. (2017). Tales of Two Islands - Lessons for EU Energy Policy from Electricity Market Reforms in Britain and Ireland, Energy Policy, Vol. 105, June, pp. 597-607.

Oseni, M. O., and Pollitt, M. G. (2016). The promotion of regional integration of electricity markets: lessons for developing countries. Energy Policy, 88, 228-238.

Pantos, T., Polyzos, S., Armenatzoglou, A., and Kampouris, I. (2019). Volatility Spillovers in Electricity Markets: Evidence from the United States. International Journal of Energy Economics and Policy, 19, 131-143.

Patton, A., and Sheppard, K. (2015). Good volatility, bad volatility: Signed jumps and the persistence of volatility. Review of Economics and Statistics, 97, 683-697.

Pen Le, Y., and Sevi, B. (2010). Volatility transmission and volatility impulse response functions in European electricity forward markets. Energy Economics, 32, 758-770.

Phillips, P., and Sul, D. (2007). Transition modelling and econometric convergence tests. Econometrica, 75, 1771-1855.

Phillips, P., and Sul, D. (2009). Economic transition and growth. Journal of Applied Econometrics, 24, 1153-1185.

Pollitt, M. (2019). The European Single Market in Electricity: An Economic Assessment. Review of Industrial Organisation, 55, 63-87.

Pollitt, M. G. (2017). The economic consequences of Brexit: energy. Oxford Review of Economic Policy, 33, 134-143.

Qu, H., Duan, Q., and Niu, M. (2018). Modeling the volatility of realized volatility to improve volatility forecasts in electricity markets. Energy Economics, 74, 767-776.

Nepal.R and Jamasb. T. (2012). Interconnections and market integration in the Irish Single Electricity Market. Energy Policy, 51, 425-434. 
Sadorsky, P. (2012). Correlations and volatility spillovers between oil prices and the stock prices of clean energy and technology companies. Energy Economics, 34, 248-255.

SEAI. (2017). Electricity and gas prices in Ireland: 2nd semester (July-December) 2016. Sustainable Energy Authority of Ireland.

Segal, G., Shaliastovich, I., and Yaron, A. (2015). Good and bad uncertainty: macroeconomic and financial market implications. Journal of Financial Economics, 117, 369-397.

Sela, R. J., and Hurvich, C. M. (2009). Computationally efficient methods for two multivariate fractionally integrated models. Journal of Time Series Analysis, 30, 631-651.

Singh, A., Jamasb, T., Nepal, R., and Toman, M. (2018). Electricity cooperation in South Asia: Barriers to cross-Border Trade. Energy Policy, 120, 741-748.

Wallace, B. (2019). Brexit and the Irish Electricity Sector - What are the Potential Impacts. Retrieved from https://byrnewallace.com/news-and-recent-work/publications/brexitirish-electricity-sector.html

Woo, C. K., Lloyd-Zanetti, D., and Horowitz, I. (1997). Electricity market integration in the Pacific Northwest. Energy Journal, 18, 75-101.

Worthington, A. C., Kay-Sparately, A., and Higgs, H. (2005). Transmission of Prices and Price Volatility in Australian Electricity Spot Markets: A Multivariate GARCH Analysis. Energy Economics, 27, 337-350.

Yip, P., Brooks, R., and Do, H. (2017). Dynamic spillover between commodities and commodity currencies during United States Q.E. Energy Economics, 66, 399-410.

Zachmann, G. (2008). Electricity wholesale market prices in Europe: Convergence? Energy Economics, 30, 1639-1671. 